\title{
Corrigendum: Developing Pre-service Teachers Conceptualization of STEM and STEM Pedagogical Practices
}

\author{
Fatlume Berisha and Eda Vula* \\ Faculty of Education, University of Prishtina "Hasan Prishtina", Prishtina, Kosovo
}

Keywords: STEM, mathematics pre-service teachers, chemistry pre-service teachers, professional development, higher education

\section{Corrigendum on}

Developing Pre-Service Teachers Conceptualization of STEM and STEM Pedagogical Practices by Berisha, F., and Vula, E. (2021). Front. Educ. 6:585075. doi: 10.3389/feduc.2021.585075

In the original article, Akaygun, S., and Aslan-Tutak, F. (2020). "Collaboratively Learning to Teach STEM: A Model for Learning to Integrate STEM Education in Preservice Teacher Education," in Critical Questions in STEM Education. Contemporary Trends and Issues in Science Education. Editors V. I. Akerson, and G. A. Buck (Cham: Springer), Vol. 1. https://doi.org/10.1007/978-3-030-57646-2_9 was not cited in the article. The citation has now been inserted in Methodology, Paragraph Number 2, Table 1 and should read:

Initially, pre-service teachers were asked to reflect on STEM knowledge they might have and STEM conceptualization. The pre-reflection was meant to enable researchers (authors) to learn how much STEM knowledge and STEM awareness pre-service teachers had. For 5 weeks in a row, the STEM professional development workshop was attended by pre-service teachers on Saturdays. In the eighth week, pre-service teachers presented and discussed their group STEM projects. During the workshop, participants had a dual role: as learners-involved in the learning process while engaging in the STEM workshop and as teachers-involved in discussions and perspectives on pedagogical processes. Table 1 outlines the weekly activities for the STEM professional development workshop based on work of Akaygun and Aslan-Tutak, (2020). All activities were completed in groups (mainly two mathematics and two pre-service chemistry teachers). After the professional development workshop, open-ended, post-reflective questions were emailed to all participants to inquire about their experiences. In response, the understanding, knowledge, and pedagogical practices gained during the collaborative practices and the benefits/challenges they faced during the STEM workshop were acquired. A total of 26 responses were collected from all participants in the workshop (incomplete responses were not considered).

Text Correction

In the original article, there was an error. The word used "prepared" should be replaced with "replicated".

A correction has been made to Methodology, Paragraph Number 1:

The study took place at the University of Prishtina, Faculty of Education, during the academic year 2017/2018. A total of 40 (22 mathematics and 18 chemistry) pre-service teachers engaged voluntarily in the professional development workshop organized and structured by mathematics and chemistry university lecturers (authors) associated with the needs provoked during the Teaching and Learning of subject-specific courses at Master-level studies. The lecturers replicated the module developed by Dr. Sevil Akaygun and Dr. Fatma Aslan-Tutak from the Bogazici University (Akaygun 
TABLE 1 | The activities for the STEM professional development workshop (Akaygun and Aslan-Tutak, 2020).

Week

1

2

3

4

5

8

8

\section{Schedule}

Pre-reflection on STEM knowledge

Activity 1: Introduction to STEM education

Lecture on STEM education

Two scientific articles on STEM education were shared with the pre-service teachers for reading and reflection (Dugger,

2010; Laboy-Rush, 2011)

Activity 2: Poster of STEM Student Club Logo

Visioning of STEM through drawing (students were given A3 paper size and crayons)

Reflection on the activity

Activity 3: Edible Car

Guided worksheet instructed for planning, designing, and testing the speed of movement of the "Edible Car."

Different foods were provided

Reflection on the activity

Activity 4: Ocean Color

Guided worksheet through QR code reader for planning, designing, testing ocean colors

Reflection on the activity

Activity 5: Building a boat

Guided worksheet for planning, designing, testing if the ship will sink or float

Recycling materials provided

Reflection on the activity

Activity 5: Build your Project and lesson worksheets for planning, designing and testing

Post-reflection questions on STEM and Aslan-Tutak, 2020) with their collaboration and organized STEM workshop activities to introduce practices that support STEM education.

\section{REFERENCES}

Akaygun, S., and Aslan-Tutak, F. (2020). "Collaboratively Learning to Teach STEM: A Model for Learning to Integrate STEM Education in Preservice Teacher Education," in Critical Questions in STEM Education. Contemporary Trends and Issues in Science Education. Editors V. I. Akerson and G. A. Buck (Cham: Springer), Vol. 15. doi:10.1007/978-3-030-57646-2_9

Dugger, W. E. (2010). "Evolution of STEM in the United States," in Proceedings of the 6th Biennial International Conference on Technology Education Research'nda sunulmuş bildiri, Gold Coast, QL.

Laboy-Rush, D. (2011). Integrated STEM Education Through Project-Based Learning. Portland: Sematinticscholar.org. Available online at: https://studentsatthecenterhub. org/resource/integrated-stem-educationthrough-project-based-learning/.
The authors apologize for this error and state that this does not change the scientific conclusions of the article in any way. The original article has been updated.

Publisher's Note: All claims expressed in this article are solely those of the authors and do not necessarily represent those of their affiliated organizations, or those of the publisher, the editors and the reviewers. Any product that may be evaluated in this article, or claim that may be made by its manufacturer, is not guaranteed or endorsed by the publisher.

Copyright $\odot 2021$ Berisha and Vula. This is an open-access article distributed under the terms of the Creative Commons Attribution License (CC BY). The use, distribution or reproduction in other forums is permitted, provided the original author(s) and the copyright owner(s) are credited and that the original publication in this journal is cited, in accordance with accepted academic practice. No use, distribution or reproduction is permitted which does not comply with these terms. 